\title{
Analysis of Crack Susceptibility of Regular Carbon Steel Slabs Using Volume-Based Shrinkage Index
}

\author{
Jianfei $X U^{11}$ Shengping $\mathrm{HE}_{,}{ }^{1) *}$ Xueping $\mathrm{JIANG}{ }^{2)}$ Ting $\mathrm{WU}^{1)}$ and Qian WANG ${ }^{1)}$ \\ 1) College of Materials Science and Engineering, Chongqing University, Chongqing, 400044 China. \\ 2) Iron \& Steel Research Institute, Chongqing Iron \& Steel, Chongqing, 401258 China.
}

(Received on February 3, 2013; accepted on June 12, 2013)

\begin{abstract}
The degree of peritectic solidification is a strong indicator of the cracking tendency of steel during continuous casting. To predict the crack susceptibility of regular carbon steel slabs, the characteristic index of solidification shrinkage ( $\left.R_{v}\right)$, which is determined by the volume shrinkage of the peritectic solidification and the remaining liquid phase after the peritectic solidification, is proposed as a means of evaluating the cracking tendency. In this study, $R_{V}$ was calculated for different steel grades under equilibrium condition. Then the segregation of the elements and the zone of the peritectic solidification under non-equilibrium condition were discussed with respect to the cooling rate. The results show that the calculated $\mathrm{R}_{\mathrm{V}}$ was in good agreement with experimental observations made on steel slabs, based on the zone of peritectic solidification under non-equilibrium condition. Rv can therefore be used to predict the crack susceptibility of regular carbon steel slabs.
\end{abstract}

KEY WORDS: continuous casting; crack susceptibility; characteristic index of solidification shrinkage; nonequilibrium.

\section{Introduction}

The characteristics of peritectic solidification in continuous casting have a great effect on the continuously cast slabs. During the actual process of producing peritectic steel, a large volume shrinkage occurs in the transformation from austenite to ferrite, which produces a large shrinkage stress and causes the solidified shell to grow unevenly. Longitudinal cracks will occur in the surface of the solidified shell if the meniscus region cannot conduct heat uniformly. ${ }^{1-5}$

During the peritectic solidification, the peritectic phase transition occurs in two stages: the peritectic reaction $(\mathrm{L}+\delta \rightarrow \gamma)$ and the peritectic transformation $(\mathrm{L} \rightarrow \gamma$ and $\delta \rightarrow \gamma){ }^{6}$ ) Once the peritectic reaction is complete and the L/ $\delta$ interface is covered by austenite, the peritectic transformation begins. The rates of both the peritectic reaction and the peritectic transformation influence the crack susceptibility by affecting the volume shrinkage. ${ }^{7)}$

Many researchers have proposed different methods to estimate the solidification cracking tendency during continuous casting. Matsumiya et ll $^{8)}$ proposed using the density change during the peritectic solidification to analyze the crack susceptibility, and they suggested that the strain developed in a brittle temperature range of $\mathrm{T}_{\mathrm{a}}-30^{\circ} \mathrm{C}<\mathrm{T}<\mathrm{T}_{\mathrm{a}}$ was maximized at 0.14 mass $\% \mathrm{C}$, where $\mathrm{T}_{\mathrm{a}}$ was the temperature at a solid fraction of 0.85 in the $\mathrm{Fe}-\mathrm{C}$ binary system. Harste et al. ${ }^{9)}$ used mechanical model and thermal model to predict the crack susceptibility, they found that there was a shrink-

* Corresponding author: E-mail: heshp@cqu.edu.cn

DOI: http://dx.doi.org/10.2355/isijinternational.53.1812 age peak at about 0.1 mass $\%$ C. However, the effect of other solute elements on the cracking tendency was ignored in the above research. Clyne et al. ${ }^{10)}$ proposed a crack susceptibility coefficient to estimate the cracking tendency, they divided the mushy zone into the liquid feeding zone and the cracking zone. Meanwhile, some other researchers estimated the cracking tendency based on the strain and stress. Specifically, Won et al. ${ }^{11)}$ proposed the concept of "Specific Crack Susceptibility" to analyze the cracking tendency based on the critical fracture stress and critical stain. However, too many parameters were introduced in their model and the calculation process was also too complicated to be adopted for widespread application in actual production processes.

Therefore, the present study proposes a quantitative model that is more easily understood for the comprehensively analysis of the crack susceptibility. The degree of the peritectic solidification, which depends on the volume shrinkage and the mass of the peritectic solidification, was considered, and a characteristic index of solidification shrinkage is proposed to interpret and predict the crack susceptibility of regular carbon steels slabs.

\section{Characterization of Shrinkage during Solidification Process}

The shrinkage of steel during the solidification process is related to the carbon content, as shown by the example for $\mathrm{Fe}-\mathrm{C}$ steel in Fig. 1 with 0.34 mass\% $\mathrm{Si}, 1.52$ mass\% $\mathrm{Mn}$, $0.012 \% \mathrm{P}, 0.015$ mass $\% \mathrm{~S}$ and 0.03 mass $\% \mathrm{Al}$.

Figure 1 shows that the sequence of phase changes is: 


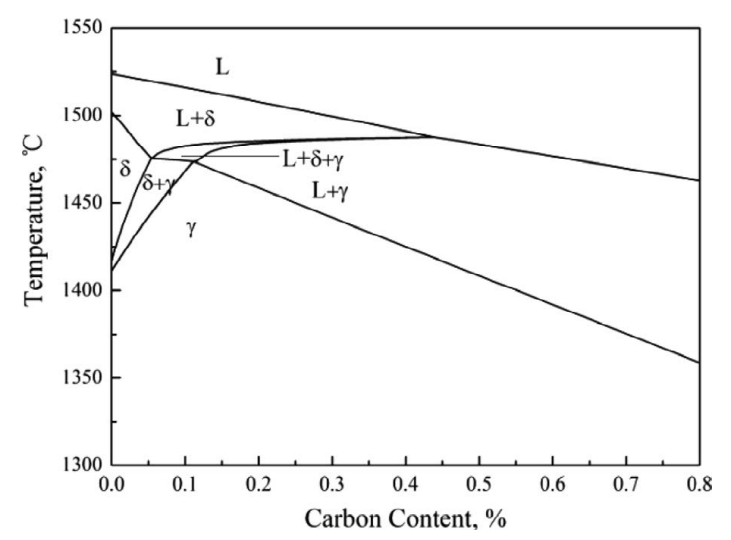

Fig. 1. Fe-C-0.34 mass\% $\mathrm{Si}-1.52$ mass\% $\mathrm{Mn}-0.012$ mass\% $\%$ 0.015 mass $\% \mathrm{~S}-0.03$ mass $\% \mathrm{Al}$ phase diagram.

$\mathrm{L} \rightarrow \mathrm{L}+\delta \rightarrow \mathrm{L}+\delta+\gamma \rightarrow \delta+\gamma$ when the actual carbon content is to the left of the peritectic point, and $\mathrm{L} \rightarrow \mathrm{L}+\delta \rightarrow \mathrm{L}+\delta+\gamma \rightarrow \mathrm{L}+\gamma \rightarrow \gamma$ when the actual carbon content is to the right of the peritectic point. Peritectic solidification occurs in a narrow temperature range, in contrast, $\mathrm{L} \rightarrow \mathrm{L}+\delta$ and $\mathrm{L}+\gamma \rightarrow \gamma$ occur in a larger temperature range, which help relieve the shrinkage stress effectively in time. Meanwhile, by "in-situ" observations of the peritectic solidification with a confocal scanning laser microscope, Shibata et al. ${ }^{7)}$ found that it just needs $2 / 30 \mathrm{~s}$ for the peritectic solidification of $\mathrm{Fe}-0.14$ mass $\% \mathrm{C}$ alloy at a cooling rate of $10 \mathrm{~K} / \mathrm{min}$, Moon et al ${ }^{12)}$ found that only $0.07 \mathrm{~s}$ were required for the peritectic solidification of $\mathrm{Fe}-$ 0.085 mass $\% \mathrm{C}-2.8$ mass $\% \mathrm{Mn}-1.0$ mass $\% \mathrm{Si}-0.016$ mass $\% \mathrm{Ti}$ at a cooling rate of $20 \mathrm{~K} / \mathrm{min}$. The rapidness of the peritectic solidification makes it difficult for the resulting stress to be released in time, which increases the cracking tendency of steel, and the greater the volume shrinkage, the greater the stress is. Thus the volume shrinkage caused by the peritectic solidification is an important factor in determining the cracking tendency of steel during the solidification process.

In addition, there is no liquid phase after peritectic solidification for hypo-peritectic steel while some remains for hyper-peritectic steel. On the one hand, the volume shrinkage can be partly refilled by the remaining liquid phase, ${ }^{13)}$ which would lower the crack susceptibility to some degree. On the other hand, the remaining liquid phase doesn't participate in peritectic solidification. For example, only $80 \%$ of the liquid phase and $\delta$ react during the peritectic solidification when the mass fraction of the remaining liquid is $20 \%$. So this remaining liquid phase should be deducted.

Therefore, the characteristic index of solidification shrinkage $\left(\mathrm{R}_{\mathrm{V}}\right)$ was used to determine the cracking tendency of steel. It is calculated as follows:

$$
\mathrm{R}_{\mathrm{V}}=\Delta \mathrm{V}(1-\mathrm{L})
$$

where $\mathrm{L}$ is the mass fraction of the remaining liquid phase after the peritectic solidification, which is obtained by the lever rule, and $\Delta \mathrm{V}$ is the volume shrinkage of the peritectic solidification, which is determined by the steel density before and after the peritectic solidification.

$$
\Delta \mathrm{V}=\frac{1 / \rho_{1}-1 / \rho_{2}}{1 / \rho_{1}}
$$

Here, $\rho_{1}$ is the density of $(\mathrm{L}+\delta)$, and $\rho_{2}$ is the density of $\gamma,(\mathrm{L}+\gamma)$ or $(\delta+\gamma)$.
The density of steel was obtained as follows: ${ }^{14)}$

$$
\begin{aligned}
& \rho_{\mathrm{L}+\delta}=\rho_{\mathrm{L}}{ }^{0}+\Delta \rho_{\mathrm{L}+\delta} \times \mathrm{f}_{\delta}\left(\times 10^{3} \mathrm{~kg} / \mathrm{m}^{3}\right) \\
& \rho_{\mathrm{L}+\gamma}=\rho_{\mathrm{L}}^{0}+\Delta \rho_{\mathrm{L}+\gamma} \times \mathrm{f}_{\gamma}\left(\times 10^{3} \mathrm{~kg} / \mathrm{m}^{3}\right) . \\
& \rho_{\delta}=3.07 \times 10^{-4}\left(\mathrm{~T}_{\delta \text {,start }}-\mathrm{T}\right)+7.27\left(\times 10^{3} \mathrm{~kg} / \mathrm{m}^{3}\right) \\
& \rho_{\gamma}=4.80 \times 10^{-4}\left(\mathrm{~T}_{\gamma, \text { start }}-\mathrm{T}\right)+7.41\left(\times 10^{3} \mathrm{~kg} / \mathrm{m}^{3}\right) \text {. } \\
& \rho_{\mathrm{L}}=-7.50 \times 10^{-4}\left(\mathrm{~T}-\mathrm{T}_{\mathrm{L}, \text { start }}\right)+7.02\left(\times 10^{3} \mathrm{~kg} / \mathrm{m}^{3}\right) . \\
& \rho_{\delta+\gamma}=\rho_{\delta} \times \mathrm{f}_{\delta}+\rho_{\gamma} \times \mathrm{f}_{\gamma}\left(\times 10^{3} \mathrm{~kg} / \mathrm{m}^{3}\right)
\end{aligned}
$$

where $\rho_{\mathrm{i}}$ is the density of the i phase, $\rho_{\mathrm{i}}^{o}$ is the density at the liquidus temperature, and $\Delta \rho_{\mathrm{i}}$ is the difference of density between the liquidus and solidus of the i phase.

The temperature in the various solid fractions ${ }^{15)}$ was calculated according to the Eqs. (9)-(12):

$$
\begin{aligned}
& \mathrm{T}=1536-\left[\Sigma \mathrm{f}\left(\mathrm{C}_{\mathrm{i}}\right)\right] \times\left[1-\mathrm{f}_{\mathrm{s}}(1-2 \Omega \mathrm{k})\right]^{(\mathrm{k}-1) /(1-2 \Omega \mathrm{k})} \\
& {\left[\Sigma \mathrm{f}\left(\mathrm{C}_{\mathrm{i}}\right)\right]=67.51[\% \mathrm{C}]+9.741[\% \mathrm{Si}]+3.292[\% \mathrm{Mn}]} \\
& +82.18[\% \mathrm{P}]+155.8[\% \mathrm{~S}] \text {. } \\
& \Omega=\alpha(1-\exp (-1 / \alpha))-1 / 2 \exp (-1 / 2 / \alpha) \\
& \alpha=33.7 \mathrm{R}_{\mathrm{C}}^{-0.244}
\end{aligned}
$$

where $R_{c}$ is the cooling rate $(0.01 \mathrm{~K} / \mathrm{s}$ under equilibrium condition and $10 \mathrm{~K} / \mathrm{s}$ under non-equilibrium condition), $\mathrm{f}_{\mathrm{s}}$ is the solid fraction, and the value of $\mathrm{k}$ is 0.265 .

Next, considering the complexity of the solidification process, values of $R_{V}$ were calculated for different steel grades under equilibrium and non-equilibrium condition.

(1) Equilibrium condition

To calculate the $\mathrm{R}_{\mathrm{V}}$ under equilibrium condition, the carbon contents of the peritectic starting point $\left(\mathrm{C}_{S}\right)$, peritectic point $\left(\mathrm{C}_{\mathrm{P}}\right)$ and peritectic end point $\left(\mathrm{C}_{\mathrm{L}}\right)$ were obtained by multi-component $\mathrm{Fe}-\mathrm{C}$ phase diagrams calculated by FactSage. The mass fractions of the liquid phase (L), $\delta$ and $\gamma$ before and after the peritectic solidification were determined by the lever rule according to the Eqs. (13)-(20):

(1) before the peritectic solidification

$$
\begin{array}{r}
\mathrm{L}=\left(\mathrm{C}_{\mathrm{P}}-\mathrm{C}_{\mathrm{S}}\right) /\left(\mathrm{C}_{\mathrm{L}}-\mathrm{C}_{\mathrm{S}}\right) . \\
\delta=\left(\mathrm{C}_{\mathrm{L}}-\mathrm{C}_{\mathrm{P}}\right) /\left(\mathrm{C}_{\mathrm{L}}-\mathrm{C}_{\mathrm{S}}\right) . \\
\gamma=0 . \ldots \ldots \ldots \ldots
\end{array}
$$

(2) after the peritectic solidification

$$
\begin{aligned}
& \mathrm{L}=\left(\mathrm{C}_{0}-\mathrm{C}_{\mathrm{P}}\right) /\left(\mathrm{C}_{\mathrm{L}}-\mathrm{C}_{\mathrm{P}}\right)\left(\mathrm{C}_{\mathrm{O}}>\mathrm{C}_{\mathrm{P}}\right) . \\
& \mathrm{L}=0\left(\mathrm{C}_{\mathrm{O}} \leq \mathrm{C}_{\mathrm{P}}\right) \ldots \\
& \delta=0\left(\mathrm{C}_{\mathrm{O}}>\mathrm{C}_{\mathrm{P}}\right) \text {. } \\
& \delta=\left(\mathrm{C}_{\mathrm{P}}-\mathrm{C}_{0}\right) /\left(\mathrm{C}_{\mathrm{P}}-\mathrm{C}_{\mathrm{S}}\right)\left(\mathrm{C}_{\mathrm{O}} \leq \mathrm{C}_{\mathrm{P}}\right) . \\
& \gamma=1-\mathrm{L}-\delta \text {. }
\end{aligned}
$$

The temperature and density of steel before and after the peritectic solidification were then calculated by Eqs. (9)(12) and (3)-(8), respectively, and Rv under equilibrium condition was thus obtained from the density of steel before and after the peritectic solidification and the mass fraction of the liquid phase after the peritectic solidification.

(2) Non-equilibrium condition

Mikio $^{16)}$ and Muojekwu et al. ${ }^{17)}$ confirmed that the initial cooling rate of the solidifying shell is approximately $10 \mathrm{~K} / \mathrm{s}-$ 
$100 \mathrm{~K} / \mathrm{s}$. In addition, Jablonka et al. ${ }^{18)}$ presented a $\mathrm{Fe}-\mathrm{C}$ phase diagram at different degree of supercooling, as shown in Fig. 2.

The thermal shrinkage also changes at different degree of supercooling, ${ }^{18)}$ as shown in Fig. 3.

Figures 2 and 3 show that the peritectic point and the greatest thermal shrinkage move toward bottom left when the degree of supercooling is increased. On this basis, Hu. et al. ${ }^{19)}$ reported that the cooling rate causes the carbon content of the peritectic point to move toward the left by 0.03 mass $\%$ for slabs and 0.07 mass $\%$ for CSP, so the zone of the peritectic solidification under non-equilibrium condition would move toward the bottom left.

At the same time, the cooling rate promotes the segregation of the elements, the composition of elements in the solidified front will always be changing, as will the zone of the peritectic solidification.

Therefore, the segregation of elements and the zone of peritectic solidification under non-equilibrium condition were discussed with respect to the cooling rate.

(1) Segregation condition

The solute element at the solidification front would produce segregation during the solidification process, the Brody-Flemings model was adopted to calculate the segregation of elements in this study. ${ }^{20)}$ The equation of the Brody-Flemings model is shown as follows:

$$
\mathrm{C}_{\mathrm{L}}=\mathrm{Co}_{\mathrm{O}}\left(1+\mathrm{f}_{\mathrm{s}}(\beta \mathrm{k}-1)\right)^{(1-\mathrm{k}) /(\beta \mathrm{k}-1)}
$$

where $f_{S}$ is the solid fraction, $k$ is the equilibrium distri-

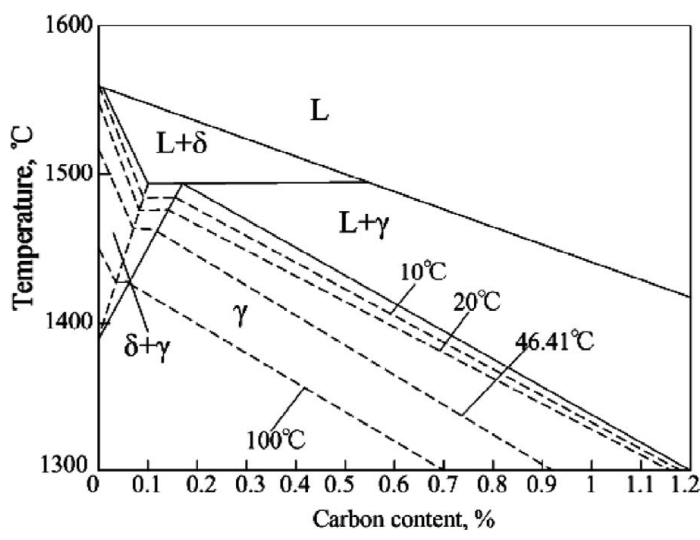

Fig. 2. $\mathrm{Fe}-\mathrm{C}$ phase diagram at different degree of supercooling.

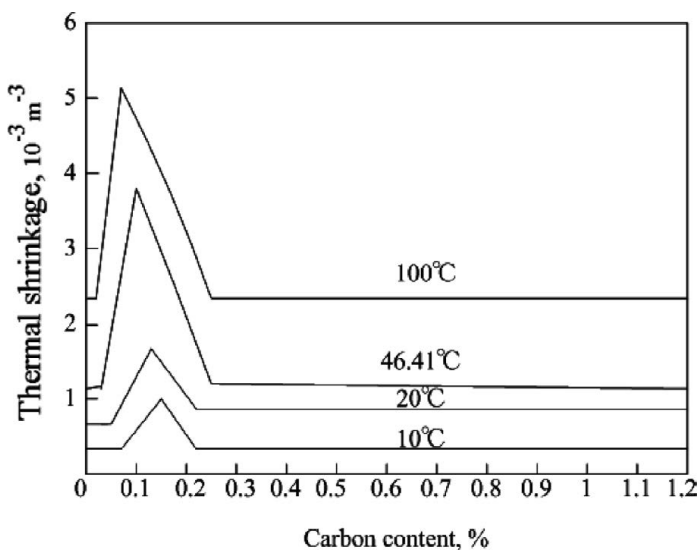

Fig. 3. Thermal shrinkage at different degree of supercooling. bution coefficient, $\mathrm{C}_{\mathrm{O}}$ is the initial concentration, $\mathrm{C}_{\mathrm{L}}$ is the concentration of the solidification front, and $\beta$ is the correction factor given as follows:

$$
\begin{aligned}
& \beta=2 \alpha(1-\exp (-1 / \alpha))-\exp (-1 / 2 / \alpha) \\
& \alpha=4 \mathrm{D}_{\mathrm{st}} / \lambda^{2} .
\end{aligned}
$$

In Eq. (22), $\alpha$ is the Fourier number of the solute, $D_{S}$ is the diffusion coefficient of the solute in the solid phase, $\mathrm{t}_{\mathrm{f}}$ is the local solidification time, and $\lambda$ is the secondary dendrite arm spacing given as follows:

$$
\lambda=\left(169.1-720.9 \times\left[\% \mathrm{C}_{\mathrm{C}}\right]\right) \times \mathrm{R}_{\mathrm{C}}{ }^{-0.4935}\left[\% \mathrm{C}_{\mathrm{C}}\right] \leq 0.15
$$

$$
\lambda=143.9 \times \mathrm{R}_{\mathrm{C}}{ }^{-0.3616} \times\left[\% \mathrm{C}_{\mathrm{C}}\right]^{(0.5501-1.996[\% \mathrm{Cc}])}\left[\% \mathrm{C}_{\mathrm{C}}\right]>0.15
$$

As the composition of steel varies among the different solid fractions, the iteration method was used to determine the solid fraction before and after the peritectic reaction.

On this basis of it, $R_{V}$ could be determined under solidification segregation condition. The process of calculation is shown in Fig. 4.

(2) Zone of peritectic solidification under the non-equilibrium condition

To analyze the zone of peritectic solidification under non-equilibrium condition, the value derived by $\mathrm{Hu}$ that the cooling rate causes the carbon content of the peritectic point to move toward the left by 0.03 mass $\%$ for slabs was employed. On this basis, this study assumes the following:

Firstly, the liquid solute can be mixed fully and the spread of the solid solute is limited. That is, the cooling rate has some effect on the peritectic starting point, but little impact

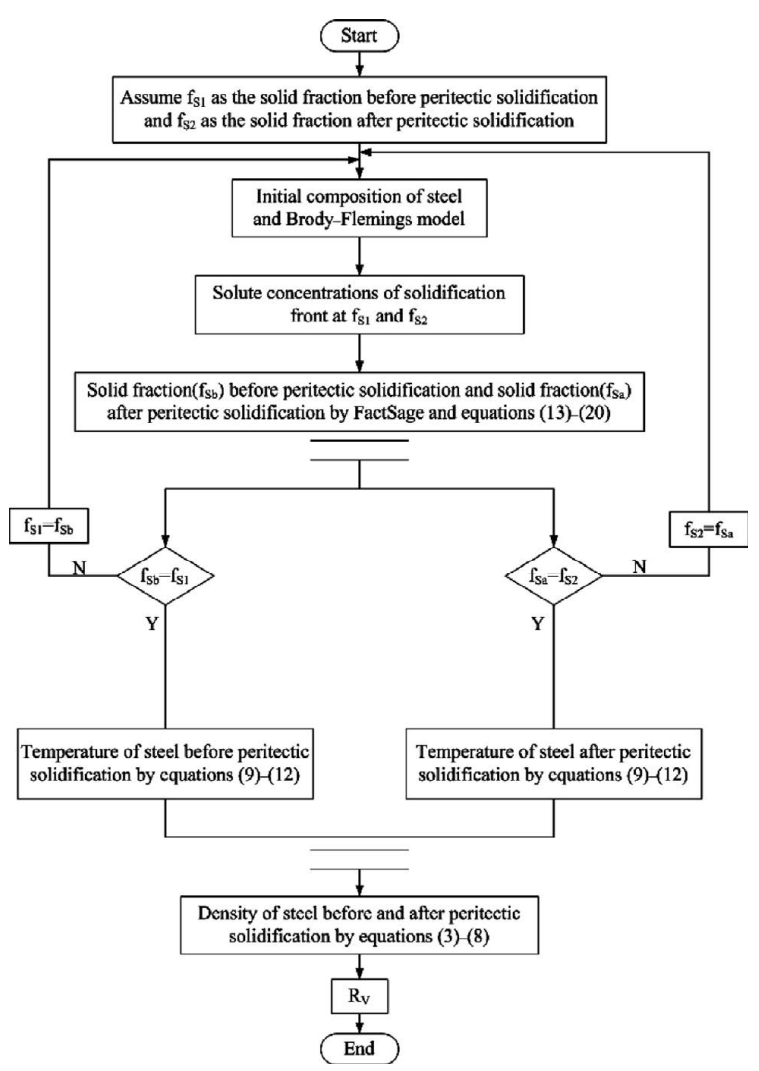

Fig. 4. Flowchart of calculating $R_{V}$ under solidification segregation condition. 
on the peritectic end point.

Secondly, the ratio of the liquid phase to $\delta$ under nonequilibrium condition is consistent with the equilibrium condition when the liquid phase and $\delta$ transform completely into $\gamma$ in the same system. This is determined by the conservation of mass, and can be used to describe the change in the peritectic starting point under non-equilibrium condition.

In the $\mathrm{Fe}-\mathrm{C}$ binary system, the carbon contents of the peritectic starting point, peritectic point and peritectic end point are $0.09,0.17$ and 0.53 mass $\%$, respectively, under equilibrium condition. In addition, the ratio of the liquid phase to $\delta$ is $0.182: 0.818$ when they completely transform into $\gamma$. Thus the carbon contents of the peritectic point and peritectic end point are 0.14 and 0.53 mass $\%$, respectively, with the existence of the cooling rate. The carbon content of the peritectic starting point is $0.054 \%$ to guarantee the ratio of the liquid phase to $\delta$, as shown in Fig. 5.

In a $\mathrm{Fe}-\mathrm{C}$ multi-component system, for example, $\mathrm{Fe}-\mathrm{C}$ with 0.3 mass $\% \mathrm{Si}, 1.2$ mass $\% \mathrm{Mn}, 0.01$ mass $\% \mathrm{P}, 0.01$ mass $\% \mathrm{~S}$ and 0.03 mass $\% \mathrm{Al}$, the calculation process can be shown in Fig. 6.

Figures 5 and 6 show that the cooling rate causes the carbon content of the peritectic starting point to move toward the left by $0.035 \%$, the zone of the peritectic reaction is thus

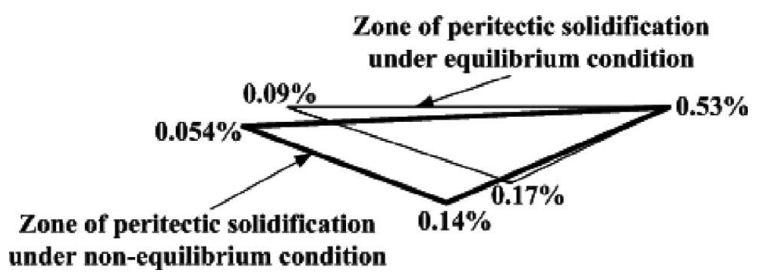

Fig. 5. Calculation process in $\mathrm{Fe}-\mathrm{C}$ binary system.

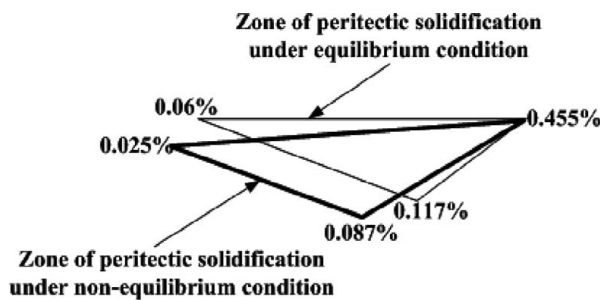

Fig. 6. Calculation process in $\mathrm{Fe}-\mathrm{C}$ multi-component system. determined in this manner, then the method for calculating $\mathrm{R}_{\mathrm{V}}$ in the zone of the peritectic solidification under nonequilibrium condition is the same as that under equilibrium condition.

\section{Industrial Testing and Validation}

To interpret and predict the crack susceptibility of steel, data on slabs obtained from 4194 heats in 2010 and 3638 heats in 2012 at an actual steel plant were statistically analyzed. The cross section of the slabs from 2010 and 2012

Table 1. Composition of steel according to carbon content from 0.09 to 0.18 mass $\%$.

\begin{tabular}{cllccl}
\hline $\mathrm{C}$ & $\mathrm{Si}$ & $\mathrm{Mn}$ & $\mathrm{P}$ & $\mathrm{S}$ & sol. Al \\
\hline 0.18 & 0.28 & 1.16 & 0.0163 & 0.0065 & 0.026 \\
0.17 & 0.3 & 1.24 & 0.0168 & 0.0056 & 0.03 \\
0.16 & 0.28 & 1.18 & 0.0172 & 0.0067 & 0.028 \\
0.15 & 0.27 & 1.14 & 0.0169 & 0.0065 & 0.03 \\
0.14 & 0.25 & 1.02 & 0.0166 & 0.0064 & 0.031 \\
0.13 & 0.23 & 0.83 & 0.0168 & 0.0068 & 0.032 \\
0.12 & 0.22 & 0.71 & 0.0165 & 0.0072 & 0.031 \\
0.11 & 0.22 & 0.67 & 0.0175 & 0.0072 & 0.03 \\
0.1 & 0.22 & 0.8 & 0.0158 & 0.0058 & 0.028 \\
0.09 & 0.21 & 0.74 & 0.0159 & 0.0046 & 0.026 \\
\hline
\end{tabular}

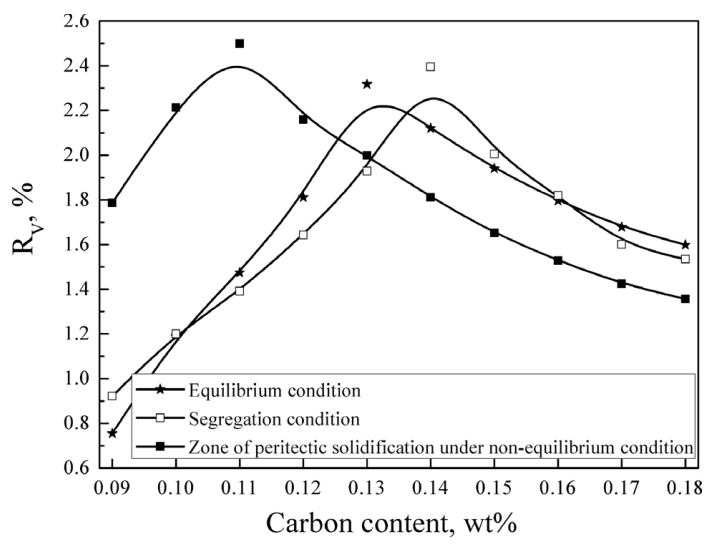

Fig. 8. Values of $\mathrm{R}_{V}$ for $0.09-0.18$ mass $\% \mathrm{C}$ under different conditions.

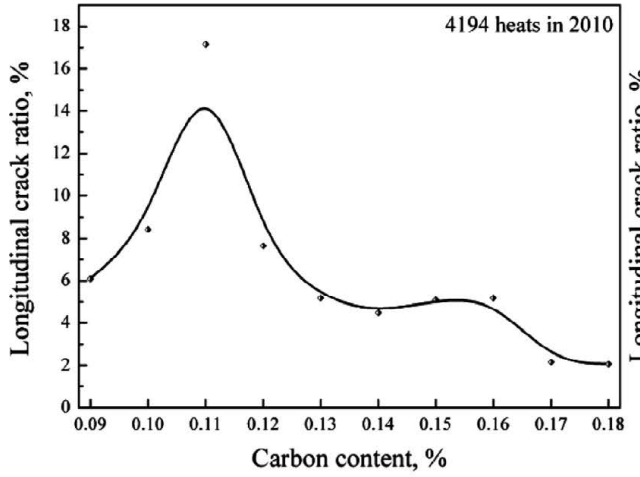

(a)

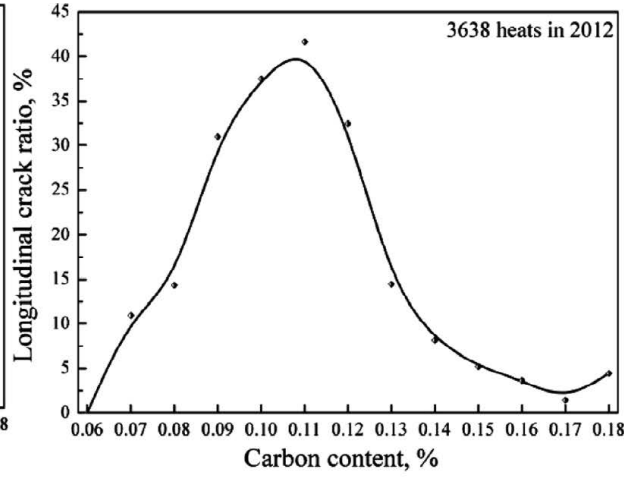

(b)

Fig. 7. Relationship between carbon content and longitudinal crack ratio. 
were $(200,250,300) \times(2000,2200,2500) \mathrm{mm}^{2}$ and $(190$, $220) \times 1530 \mathrm{~mm}^{2}$, respectively. The properties of the mold fluxes were similar, especially in the range of $0.07-0.13$ mass\% C. The casting speeds for the corresponding slabs were $0.9-1.2 \mathrm{~m} / \mathrm{min}$ and $1.3-1.58 \mathrm{~m} / \mathrm{min}$. The relationship between the carbon content and the longitudinal crack ratio for each year's data is shown in Fig. 7 .

Figure 7 shows that the longitudinal crack ratio, which is

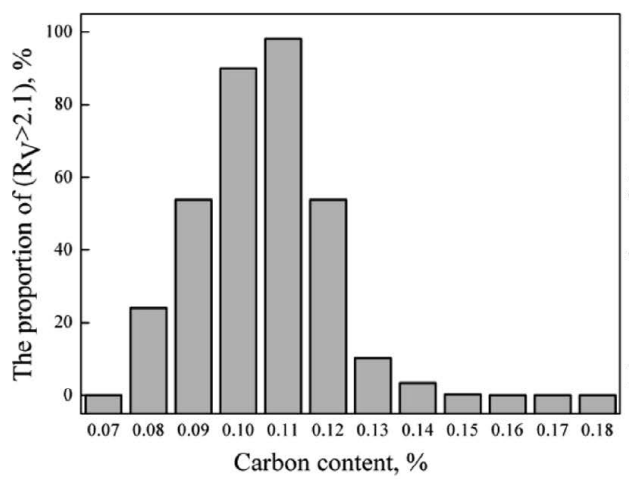

(a)

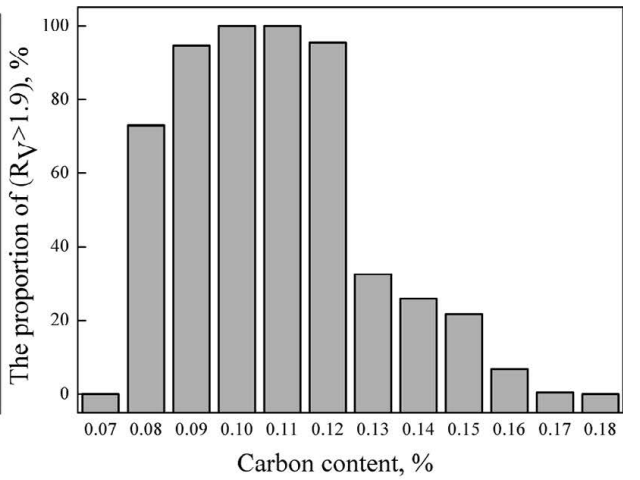

(b)

Fig. 9. Proportion of samples with $\mathrm{R}_{\mathrm{V}}$ larger than 2.1 or 1.9 for every carbon steel.
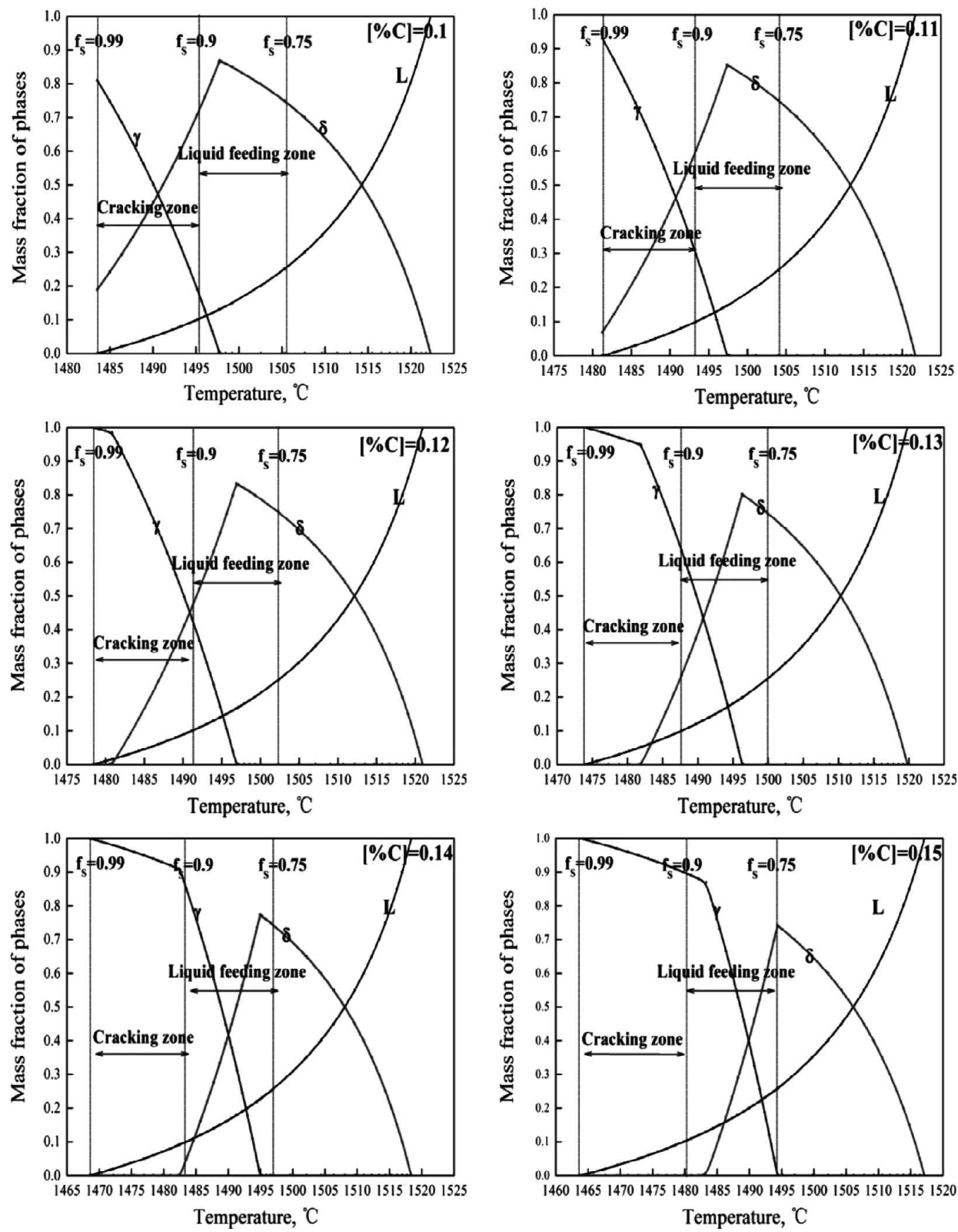

Fig. 10. Evolution of mass fraction of phases during solidification process. 
defined as the ratio of the number of slabs with longitudinal cracks to the total number, reaches its peak at a carbon content of around 0.11 mass $\%$, and the crack susceptibility was greater in the range of $0.1-0.12$ mass $\% \mathrm{C}$ for the 4194 heats in 2010 and in the range of $0.09-0.12$ mass \% C for the 3638 heats in 2012.

Next, the 4194 heats in 2010 were divided into 10 sections according to the carbon content from 0.09 to 0.18 mass $\%$. The contents of $\mathrm{Si}, \mathrm{Mn}, \mathrm{P}, \mathrm{S}$ and $\mathrm{Al}$ in steel were similar, and thus were averaged in the 10 sections, as shown in Table 1.

Subsequently, values of $\mathrm{R}_{\mathrm{V}}$ for $0.09-0.18$ mass $\% \mathrm{C}$ in the 4194 heats were calculated under different conditions, as shown in Fig. 8.

Figure 8 shows that the carbon content of largest $\mathrm{R}_{\mathrm{V}}$ is higher than 0.11 mass $\% \mathrm{C}$ under equilibrium and solidification segregation conditions. It also shows that the $\mathrm{R}_{V}$ at $0.15-0.18$ mass $\% \mathrm{C}$ is apparently higher than that at $0.09-$ 0.12 mass $\% \mathrm{C}$, though the crack susceptibility for $0.15-0.18$ mass $\% \mathrm{C}$ is not high in actual production processes. This is probably because the Brody-Flemings equation was developed for the single phase solidification, which means both the peritectic reaction and transformation are beyond the model application. However, the values of $R_{V}$ calculated in the zone of the peritectic solidification under non-equilibrium condition is in line with the statistical data, and their values at $0.15-0.18$ mass \% C appears to be lower than those at $0.09-0.12$ mass $\% \mathrm{C}$. Thus the present calculations for $\mathrm{R}_{\mathrm{V}}$ in the zone of the peritectic solidification under non-equilibrium condition can be used to predict the crack susceptibility.

To further validate the present calculations of $R_{V}$ in the zone of the peritectic solidification under non-equilibrium condition, the 3638 heats in 2012 were used to calculate $R_{V}$ for every grade of steel. In this case, the fluctuation of the composition in steel was larger. The results were then divided into four ranges according to the value of $R_{V}$ : $\left(R_{V}>2.1\right)$, $\left(\mathrm{R}_{\mathrm{V}}=1.9-2.1\right),\left(\mathrm{R}_{\mathrm{V}}=1.7-1.9\right)$ and $\left(\mathrm{R}_{\mathrm{V}}<1.7\right)$. To interpret the crack susceptibility, the proportion of samples with $\mathrm{R}_{V}$ larger than 2.1 or 1.9 was determined as shown in Fig. 9.

Figure 9 shows that the proportion of samples with $R_{V}$ larger than 2.1 is over $50 \%$ and that with $\mathrm{R}_{V}$ is greater than $80 \%$ in the range of $0.09-0.12$ mass $\% \mathrm{C}$. This is in good agreement with experimental observations of actual slabs, thus further validating the calculations.

In addition, to further understand the crack susceptibility of steel, based on the zone of the peritectic solidification under non-equilibrium condition, the evolution of the mass fraction of phases during the solidification process was also obtained in the range of $0.1-0.15$ mass $\% \mathrm{C}$ according to Table 1, as shown in Fig. 10.

During solidification process, a brittle temperature zone is divided into a liquid feeding zone and a cracking zone, and the solid fractions of the liquid feeding zone and the cracking zone are 0.75-0.9 and 0.9-0.99, depending upon the solid fractions of ZST, LIT and ZDT. The cracks formed in the liquid feeding zone can be refilled with the surrounding liquid to some degree, whereas those formed in the cracking zone cannot because the dendrite arms are sufficiently com- pacted to resist feeding of the liquid. ${ }^{10,13,21)}$ However, as shown in Fig. 10, the peritectic solidification was mainly found to occur in the liquid feeding zone where the carbon content was at least 0.14 mass $\%$. Thus the crack susceptibility at $0.1-0.13$ mass $\% \mathrm{C}$ was higher than that at 0.14 0.15 mass $\% \mathrm{C}$, which is consistent with the statistical data.

\section{Conclusions}

In order to interpret and predict the crack susceptibility of regular carbon steels, the characteristic index of solidification shrinkage $\left(\mathrm{R}_{\mathrm{V}}\right)$, which is determined by both the volume shrinkage of peritectic solidification and the remaining liquid phase after the peritectic solidification, is proposed in present study. Statistical analysis on the longitudinal crack ratio at an actual steel plant was performed to validate the present calculations. The results show that the calculated $\mathrm{R}_{\mathrm{V}}$, which was in good agreement with experimental observations made on steel slabs, based on the zone of the peritectic solidification under non-equilibrium condition, can be used to predict the crack susceptibility of regular carbon steels. The crack susceptibility of steel was further analyzed according to the evolution of the mass fractions of phases during the solidification process, and the results were consistent with experimental observations of steel slabs.

\section{Acknowledgements}

The authors would like to deeply appreciate the Fundamental Research Funds for the Central Universities in China (Project No. CDJZR11130004).

\section{REFERENCES}

1) Y. M. Won, T. J. Yeo, D. J. Seol and K. H. Oh: Metall. Mater. Trans. $B, 31 \mathrm{~B}(2000), 779$.

2) C. Cicutti and R. Boerl: Steel Res. Int., 77 (2006), 194.

3) A. Grill and J. K. Brimacombe: Ironmaking Steelmaking, 3 (1976), 76 .

4) J. Konishi, M. Militzer, J. K. Brimacombe and I. V. Samarasekera: Metall. Mater. Trans. B, 33B (2002), 413.

5) A. Jabionka, K. Harste and K. Schwerdtfeger: Steel Res., 62 (1991), 24.

6) H. W. Kerr, J. Cisse and G. F. Bolling: Acta Metall., 22 (1974), 677.

7) H. Shibata, Y. Arai, M. Suzuki and T. Emi: Metall. Mater. Trans. B, 31B (2000), 981.

8) T. Matsumiya, T. Saeki, J. Tanaka and T. Ariyoshi: Tetsu-to-Hagané, 68 (1982), 1782.

9) K. Harste and K. Schwerdtfeger: ISIJ Int., 43 (2003), 1011.

10) T. W. Clyne, M. Wolf and W. Kurz: Metall. Trans., 13B (1982), 259.

11) Y. M. Won, H. N. Han, T. J. Yeo and K. H. Oh: ISIJ Int., 40 (2000), 129.

12) S. C. Moon, R. Dippenaar and S. H. Lee: The 3rd Int. Conf. on Advances in Solidification Process, Beihai, China, (2012).

13) E. Alfaro López, M. Herrera Trejo, J. J. Ruíz Mondragón, M. Castro Román and H. Solís Tovar: ISIJ Int., 49 (2009), 851.

14) H. Mizukami and A. Yamanaka: ISIJ Int., 50 (2010), 435.

15) Y. M. Won, K. H. Kim, T. J. Yeo and K. H. Oh: ISIJ Int., 38 (1998), 1093.

16) M.Suzuki and Y.Yamaoka: Mater. Trans., 44 (2003), 836.

17) C. A. Muojekwu, I. V. Samarasekera and J. K. Brimacombe: Metall. Mater. Trans. B, 26 (1995), 361.

18) A. Jablonka, K. Harste and K. Schwerdtfeger: Steel Res., 62 (1991), 24.

19) Z. G. Hu, C. L. Ma and Y. C. Zhou: J. Iron Steel Res., 18 (2006), 10.

20) Y. M. Won and B. G. Thomas: Metall. Mater. Trans. A, 32A (2001), 1756.

21) K. H. Kim, T. J. Ye, K. H. Oh and D. N. Lee: ISIJ Int., 36 (1996), 284. 